\title{
Clinical correlation with pathology of placenta in medical disorders of pregnancy and its comparison in normal pregnancy
}

\author{
Ratnamala Siddheshware, Sunil S. Patil*, Pradip W. Sambarey
}

\begin{abstract}
Department of Obstetrics and Gynaecology, B J Government Medical College and Sassoon Hospital, Pune,
\end{abstract} Maharashtra, India

Received: 18 October 2016

Revised: 11 November 2016

Accepted: 15 November 2016

\author{
*Correspondence: \\ Dr. Sunil S. Patil, \\ E-mail: sunilpati10332@gmail.com
}

Copyright: () the author(s), publisher and licensee Medip Academy. This is an open-access article distributed under the terms of the Creative Commons Attribution Non-Commercial License, which permits unrestricted non-commercial use, distribution, and reproduction in any medium, provided the original work is properly cited.

\begin{abstract}
Background: Healthy placenta is responsible for maintaining pregnancy and promoting normal foetal development. It reflects the intrauterine status of the foetus.

Methods: In the present prospective study, total 50 Placentae from Medical Disorders of Pregnancies were studied and compared with equal number of Placentae from normal Pregnancies.

Results: The significant macroscopic changes were calcification and infarction seen in Hypertensive Disorder. Extensive placental infarction was associated with high incidence of low APGAR (82\%) and perinatal deaths (66.67\%). No significant gross macroscopic changes were seen in Anaemia, Diabetes Mellitus and Heart Disease. Increased syncytial knots, fibrinoid degeneration, vasculo-syncytial membrane paucity were significant microscopic changes in Hypertensive Disorder. In Anaemia stromal fibrosis, increased syncytial knots were seen, whereas in Diabetes Mellitus villous edema was the most significant microscopic finding. No significant microscopic change was found in Heart Disease. Increased syncytial knots, fibrinoid degeneration, vasculo-syncytial membrane paucity, stromal fibrosis were associated with increased perinatal mortality.

Conclusions: Gross and microscopic examination of placenta is strongly recommended in cases where maternal comorbid conditions is likely to have an adverse perinatal outcome.
\end{abstract}

Keywords: Medical disorders, Placenta

\section{INTRODUCTION}

Placenta is a unique organ that arises de novo, directly responsible for the growth and development of the foetus in uterus. Intrauterine existence of foetus is dependent on the placenta. Healthy placenta is responsible for maintaining pregnancy and promoting normal foetal development. It reflects the intrauterine status of the foetus. ${ }^{1}$

Colombus is credited with coining phrase "placenta" in 1559 and in his work described placenta as a place where pure and perfect blood is stored for baby before birth. ${ }^{2}$ The placenta (derived from the Latin word translating as 'flat Cake) provides oxygen, nourishment, and protection to the foetus. It also has excretory and endocrine functions.

Since all anabolites needed for foetal metabolism come from the mother's blood and all catabolites are passed back into mother's circulation through placenta, the examination of placenta gives a clear idea of what had happened with the foetus when it was in the mother's womb and what is going to happen with the foetus in the future. Placental histopathological study gives retrospective diagnosis of unexplained late still birth of normally formed foetus. ${ }^{1}$ 
Various maternal systemic disorders in pregnancy attribute to the great degree of maternal, perinatal morbidity and mortality. Gestational Hypertension and established Diabetes, specifically cause more destruction of placenta and alter its functions leading to insufficiency of placenta. The placental examination in such cases can give valuable information regarding the exact etiopathogenesis of disorders as well as foetal affection.

It is fanciful to assume that every adverse perinatal outcome is associated with an abnormal placenta, and equally fanciful to expect that every abnormal placenta will result in adverse perinatal outcome. So 'the placenta' is the most accurate record of the infants prenatal experience'. The placental study provides a record, to plan the future care of the mother and the child. In this study, an attempt is made to study various histopathological changes in placenta of commonly encountered medical disorders of pregnancies Pregnancy with a) Hypertensive Disorders b) Heart Disease c) Anaemia d) Diabetes Mellitus.

These changes are compared with placenta of patient with normal pregnancy. The pathological changes are also correlated with the perinatal outcome.

\section{Aims and objectives}

1. To study pathology (morphology and histology) of placenta in medical disorders of pregnancy.
2. To compare the findings of placenta in normal pregnancy with patient having medical disorder.

3. To establish possible correlation between placental lesion and fetal outcome.

\section{METHODS}

The prospective study clinical correlation with pathology of placenta in medical disorders of pregnancy and its comparison in normal pregnancy" was carried out in BJGMC and Sassoon hospital Pune during January 2014 to July 2015.

The total no. of placentae studied was 100 . Total 50 placentae from Normal Term Pregnancy were taken as control group and an equal number from patients with Hypertensive Disorders, Anaemia, Heart Disease and Diabetes Mellitus were studied. As the cases from the respective groups mentioned above were admitted either in Antenatal Ward or in Labour Room, detailed obstetric and medical history was recorded or clinical examination was done. The placentas were collected soon after delivery for morphological and for histopathological examination with necessary precautions. The gross lesions on cut surface as well as maternal and fetal surfaces were noted. The sections were taken from grossly abnormal areas.

\section{RESULTS}

Table 1: Distribution of cases according to age, gravida, gestational age and mode of delivery.

\begin{tabular}{|c|c|c|c|c|c|c|}
\hline Parameter & $\begin{array}{l}\text { Normal } \\
(\mathrm{n}=50)\end{array}$ & $\begin{array}{l}\text { GDM } \\
(\mathbf{n}=7)\end{array}$ & $\begin{array}{l}\text { HD } \\
(n=5)\end{array}$ & $\begin{array}{l}\text { Anaemia } \\
(n=14)\end{array}$ & $\begin{array}{l}\text { Preeclampsia } \\
(\mathrm{n}=18)\end{array}$ & $\begin{array}{l}\text { Eclampsia } \\
(n=6)\end{array}$ \\
\hline Age & $23.96 \pm 2.67$ & $30.57 \pm 3.73$ & $23.2 \pm 0.83$ & $25.14 \pm 5.03$ & $21.67 \pm 2.99$ & $23.0 \pm 3.22$ \\
\hline$P$ value & Baseline & $<0.0001^{*}$ & 0.310 & 0.242 & $0.004 *$ & 0.419 \\
\hline \multicolumn{7}{|l|}{ Groups (n) } \\
\hline $18-22(36)$ & $14(28.0)$ & 0 & 0 & $6(42.8)$ & $12(66.7)$ & $4(66.7)$ \\
\hline $23-28(52)$ & $34(68.0)$ & $1(14.3)$ & $5(100.0)$ & $4(28.6)$ & $6(33.3)$ & $2(33.3)$ \\
\hline $29-33(10)$ & $2(4.0)$ & $4(57.1)$ & 0 & $4(28.6)$ & 0 & 0 \\
\hline$>33(2)$ & 0 & $2(28.6)$ & 0 & 0 & 0 & 0 \\
\hline \multicolumn{7}{|l|}{ Gravida } \\
\hline Primi $(n=54)$ & $24(48.0)$ & $2(28.6)$ & $2(40.0)$ & $7(50.0)$ & $15(83.3)$ & $4(66.7)$ \\
\hline $2^{\text {nd }}(n=30)$ & $18(36.0)$ & $3(42.9)$ & $5(60.0)$ & $1(7.1)$ & $3(16.7)$ & $2(33.3)$ \\
\hline $3^{\text {rd }}(n=10)$ & $6(12.0)$ & $2(28.6)$ & 0 & $2(14.3)$ & 0 & 0 \\
\hline $4^{\text {th }}(n=6)$ & $2(4.0)$ & 0 & 0 & $4(28.6)$ & 0 & 0 \\
\hline \multicolumn{7}{|c|}{ GA at delivery (weeks) } \\
\hline Mean \pm SD & $37.64 \pm 1.68$ & $38.85 \pm 1.06$ & $38.8 \pm 0.83$ & $35.86 \pm 1.87$ & $33.3 \pm 3.53$ & $33.64 \pm 2.59$ \\
\hline$P$ value & Baseline & $0.070 *$ & 0.137 & $0.001 *$ & $<0.0001^{*}$ & $<0.0001^{*}$ \\
\hline \multicolumn{7}{|l|}{ Groups (n) } \\
\hline$\leq 32(14)$ & 0 & 0 & 0 & 0 & $10(55.6)$ & $4(66.7)$ \\
\hline $33-36(22)$ & $10(20.0)$ & 0 & 0 & $8(57.1)$ & $4(22.2)$ & 0 \\
\hline$\geq 37(64)$ & $40(80.0)$ & $7(100.0)$ & $5(100.0)$ & $6(42.9)$ & $4(22.2)$ & $2(33.3)$ \\
\hline \multicolumn{7}{|c|}{ Mode of delivery (n) } \\
\hline LSCS (16) & $4(8.0)$ & $6(85.7)$ & 0 & $5(35.7)$ & $1(5.6)$ & 0 \\
\hline Vaginal (84) & $46(92.0)$ & $1(14.3)$ & $5(100.0)$ & $9(64.3)$ & $17(94.4)$ & $6(100.0)$ \\
\hline
\end{tabular}


Microscopically, syncytial knots were most common finding in GDM (71.4\%), HD (60\%), anaemia (50\%), pre-eclampsia $(83 \%)$ and eclampsia (100\%). Vasculosyncytial membrane paucity was observed in $66.7 \%$ of eclampsia, $55.5 \%$ pre-eclampsia, $42.8 \%$ of GDM.
Almost all IUFD and stillborn cases show microscopic changes line syncytial knot, fibrinoid necrosis, stromal fibrosis, paucity of vasculo-syncytial membrane, hypermature villi.

Table 2: Macroscopic and microscopic abnormalities of placenta in medical disorders

\begin{tabular}{|c|c|c|c|c|c|c|}
\hline $\begin{array}{l}\text { Features } \\
(\text { Mean } \pm \text { SD) }\end{array}$ & $\begin{array}{l}\text { Normal } \\
(\mathrm{n}=50)\end{array}$ & $\begin{array}{l}\text { GDM } \\
(n=7)\end{array}$ & $\begin{array}{l}\text { HD } \\
(n=5)\end{array}$ & $\begin{array}{l}\text { Anemia } \\
(\mathrm{n}=14)\end{array}$ & $\begin{array}{l}\text { Preeclampsia } \\
(\mathrm{n}=18)\end{array}$ & $\begin{array}{l}\text { Eclampsia } \\
(n=6)\end{array}$ \\
\hline \multicolumn{7}{|c|}{ Macroscopic abnormalities } \\
\hline Macro-infarct & 0 & $5(71.4)$ & $3(60.0)$ & $7(50.4)$ & $10(55.56)$ & $4(66.67)$ \\
\hline Macro-calcification & $2(4.0)$ & $5(71.4)$ & 0 & $8(57.1)$ & $10(55.56)$ & $4(66.67)$ \\
\hline Macro-RPH & $2(4.0)$ & 0 & 0 & 0 & $3(16.7)$ & $2(33.34)$ \\
\hline \multicolumn{7}{|c|}{ Microscopic abnormalities } \\
\hline $\begin{array}{l}\text { Micro-syncytial } \\
\text { Knots }\end{array}$ & 0 & $5(71.4 \%)$ & $3(60.0 \%)$ & $7(50.0 \%)$ & $15(83.3 \%)$ & $6(100 \%)$ \\
\hline $\begin{array}{l}\text { Micro-fibrinoid } \\
\text { necrosis }\end{array}$ & 0 & $4(57.1 \%)$ & $2(40.0 \%)$ & $8(57.1 \%)$ & $8(44.4 \%)$ & $4(66.7 \%)$ \\
\hline $\begin{array}{l}\text { Micro-villous } \\
\text { congestion }\end{array}$ & 0 & $2(28.5 \%)$ & 0 & $7(50 \%)$ & $9(50 \%)$ & $3(50 \%)$ \\
\hline Micro-VSM paucity & 0 & $3(42.8 \%)$ & 0 & $2(14.2 \%)$ & $10(55.5 \%)$ & $4(66.7 \%)$ \\
\hline $\begin{array}{l}\text { Micro-stromal } \\
\text { fibrosis }\end{array}$ & 0 & $1(14.3 \%)$ & 0 & $6(42 \%)$ & $8(44.4 \%)$ & $4(66.7 \%)$ \\
\hline $\begin{array}{l}\text { Micro-Hyper } \\
\text { mature Villi }\end{array}$ & 0 & 0 & 0 & $5(35.7 \%)$ & $10(55.5 \%)$ & $3(50 \%)$ \\
\hline
\end{tabular}

Table 3: Macroscopic and Microscopic abnormalities and association with pregnancy outcomes.

\begin{tabular}{|lllll|}
\hline Features & $\begin{array}{l}\text { Normal } \\
(\mathbf{n = 7 0 )}\end{array}$ & $\begin{array}{l}\text { IUGR } \\
(\mathbf{n = 1 8})\end{array}$ & $\begin{array}{l}\text { IUFD } \\
(\mathbf{n = 6})\end{array}$ & $\begin{array}{l}\text { Still-birth } \\
(\mathbf{n = 6})\end{array}$ \\
\hline Macroscopic abnormalities & $12(17.1)$ & $14(77.7)$ & $4(66.66)$ & $4(66.66)$ \\
\hline Macro-infarct & $13(18.5)$ & $10(55.5)$ & $4(66.66)$ & $4(66.66)$ \\
\hline Macro-calcification & $2(2.8)$ & 0 & $2(33.33)$ & $3(50.0)$ \\
\hline Macro-RPH & & & & $6(100.0)$ \\
\hline Microscopic abnormalities & $16(22.8)$ & $8(44.4)$ & $6(100.0)$ & $6(100.0)$ \\
\hline Micro-syncytial Knots & $4(5.7)$ & $8(44.4)$ & $6(100.0)$ & $6(100.0)$ \\
\hline Micro-villous congestion & $12(17.1)$ & $4(22.2)$ & $4(80.0)$ & $6(100.0)$ \\
\hline Micro-fibrinoid necrosis & $3(4.2)$ & $4(22.2)$ & $6(100.0)$ & $4(80.0)$ \\
\hline Micro-VSM paucity & $1(1.4)$ & $2(11.1)$ & $4(80.0)$ & $6(100.0)$ \\
\hline Micro-stromal fibrosis & 0 & $12(66.7)$ & $6(100.0)$ & \\
\hline Micro-Hyper mature Villi & & & & \\
\hline
\end{tabular}

Calcification and infarct were evident in $17.7 \%$ and $12.9 \%$ normal birth weight placenta. Placentas in LBW had infarct in $63.6 \%$ and calcification in $36.4 \%$ whereas all cases of VLBW and ELBW patients had infarct as well as calcifications. RPH was seen in $3.2 \%, 9.1 \%$,
$40.0 \%$ and 100.0 of normal, low, very-low and extremely-low birth weight associated placentas. 


\section{DISCUSSION}

Placenta after delivery is the only vital organ in life, which can be examined without hazard to either mother or to the baby. The placenta is a paradox, as it is the only readily available organ for examination, yet one of the least studied. The potential benefits of placental examination include clarification of pathologic feature, improved management of subsequent pregnancies by diagnosing pathologic condition that may have risk of recurrence or may be preventable or treatable. The present study was undertaken to study various pathological changes in systemic disorders and to correlate the pathological changes with neonatal outcome.

Table 4: Macroscopic and microscopic abnormalities and association with birth weight.

\begin{tabular}{|lllll|}
\hline Placental features & NBW $(n=62)$ & LBW $(n=22)$ & VLBW $(n=10)$ & ELBW (n=6) \\
\hline Macroscopic abnormalities & & & & \\
\hline Macro-infarct & $8(12.9)$ & $14(63.6)$ & $10(100.0)$ & $6(100.0)$ \\
\hline Macro-calcification & $11(17.7)$ & $8(36.4)$ & $10(100.0)$ & $6(100.0)$ \\
\hline Macro-RPH & $2(3.2)$ & $2(9.1)$ & $4(40.0)$ & $6(100.0)$ \\
\hline Microscopic abnormalities & & & & $6(100.0)$ \\
\hline Micro-syncytial Knots & $12(19.4)$ & $8(36.4)$ & $10(100.0)$ & $6(100.0)$ \\
\hline Micro-villous congestion & $4(6.5)$ & $8(36.4)$ & $6(60.0)$ & $4(60.0)$ \\
\hline Micro-fibrinoid necrosis & $6(9.7)$ & $12(54.5)$ & $4(40.0)$ & $6(100.0)$ \\
\hline Micro-VSM paucity & $3(4.8)$ & $4(18.2)$ & $6(60.0)$ & $6(100.0)$ \\
\hline Micro-stromal fibrosis & $1(1.6)$ & $2(9.1)$ & $2(20.0)$ & $6(100.0)$ \\
\hline Micro-Hyper mature Villi & 0 & $8(36.4)$ & $10(100.0)$ & \\
\hline
\end{tabular}

GDM was most common in female of age group of 29-33 years, heart disease was between 23-28 age group, anaemia, pre-eclapmsia, and eclampsia was common between $18-22$. In our study $18 \%$ patients had preeclampsia and $6 \%$ had eclampsia. Anemia was found in $14 \%$, gestational diabetes mellitus (GDM) in $7 \%$ and heart disease in $5 \%$ patients. $50 \%$ had no specific medical disorder. Most of the patients with pre-eclampsia, eclampsia and anaemia were primigravida. $60 \%$ of heart disease patients and $42.9 \%$ of patients with GDM were second gravida. Mean gestational age at delivery for most of pre-eclampsia and eclampsia was $<32$ weeks, $57 \%$ of anaemia and $22.2 \%$ of pre-eclampsia patients delivered between 33-36 weeks of gestation, all patients with heart disease and GDM delivered after 37 weeks of gestation. $100 \%$ eclampsia and heart disease patient delivered vaginally, $94 \%$ of pre-eclampsia delivered vaginally, $85 \%$ of GDM patients underwent LSCS. Of anaemic patients $64.3 \%$ delivered vaginally and $35.7 \%$ required LSCS.

\section{Placental changes in abnormal pregnancy}

\section{Hypertensive disorder (Pre-eclampsia and eclampsia)}

Akhlaq $M$ et al in study of placental morphology in Preeclampsia and Eclamptic women found most of the diseased group in the slightly younger age bracket of 1828 years compared to normal pregnancy. ${ }^{3}$ In the present study $57.5 \%$ were in the age group 18 to 25 years. They also found $76 \%$ in pre-eclampsia and $78 \%$ in eclampsia delivered before term. In the present study $75 \%$ cases of Hypertensive disorder delivered before 37 weeks gestation.

Kalpana et al observed $60 \%$ low birth weight babies in Pregnancy Induced Hypertension. ${ }^{4}$ In the present study, small for gestation age babies were $21(87.5 \%)$ of all cases of Hypertensive group after 28 weeks of gestation.

Infarcts are the localised areas of ischemic villous necrosis of placenta due to lack of blood supply as a result of occlusion of the spiral arteries in the myometrium or decidua. Calcification in placentae is an ageing process, which is accentuated in Preeclampsia and Eclampsia. In their analysis of placentae in Preeclampsia and Eclampsia, Dutta et al (1985) found infarction most commonly in severe Preeclampsia (65\%), Eclampsia $(56 \%)$ followed by mild Preeclampsia (40\%). Calcification was most common in Eclampsia (59\%). Akhalaq $\mathrm{M}$ et al observed infarcts most commonly in Eclampsia (62\%) followed by Severe Preeclampsia. ${ }^{3}$ Calcification was seen most commonly in severe Preeclampsia.

In the present study, calcification was present in $58.33 \%$ of cases and infarcts were seen in $66.66 \%$ cases in Severe Pre-Eclampsia. Calcification was seen in $66.6 \%$ cases of Eclampsia and infarcts were also seen in $66.6 \%$ cases.

Akhlaq $\mathrm{M}$ et al found 14\% retroplacental haematoma in their study. 
In the present study, retroplacental haematoma was seen in $20.84 \%$ cases. This is higher than these studies. This may be due to late presentation of cases in hospital.

Syncytial knots are composed of aggregates of small, closely packed densely staining nuclei protruding from the villous surface into the intervillous space. Increased syncytial knots in placentae in Pre-eclampsia and Eclampsia suggest an attempt being made to form new villi so as to increase an effective surface area for exchange. Syncytial knots in more than $30 \%$ of the villi are considered excessive.

Narsimha A et al found increased syncytial knots (90.4\%) in pre eclampsia and eclampsia, whereas Akhlaq $\mathrm{M}$ et al found increased syncytial knots in $56 \%$ of cases of Preeclampsia and Eclampsia. ${ }^{6}$ In the present study, the increased syncytial knots were observed in $83 \%$ in PreEclampsia and in all cases of Eclampsia.

There in tendency of an excessive incidence of fibrinoid degeneration of villi in placentae of Pre-Eclampsia. Narsimha A et al found fibrinoid degeneration in $97.82 \%$ of Pre-eclampsia, whereas Akhlaq $\mathrm{M}$ et al found it in $38 \%$. In the present study, fibrinoid degeneration was found in $44 \%$ of mild and severe Pre-eclampsia and $66.6 \%$ in Eclampsia.

Vasculo-syncytial membrane counts measure the approximation of the villi to optimal maturity and hence give a good indication of the ability of the placenta to supply oxygen to the foetus. Placentae with 6 - 30 percent of the villi showing Vasculo-syncytial membranes are said to have a normal count. The paucity of the vasculosyncytial membrane is an index of fetal hypoxia. The incidence of vasculosyncytial membrane deficiency $(<6 \%)$ was $93.65 \%$ in the study of Narsimha A et al. ${ }^{6}$ They observed paucity of the vasculo-syncytial membrane to be in higher grades of toxemia correlating with the severity of the disease. Akhlaq $\mathrm{M}$ et al found it in $30 \%$ of Preeclampsia. Narsimha A et al observed vasculosyncytial paucity in $93.65 \%$ of Preeclampsia and Eclampsia. In the present study vasculo-syncytial membrane paucity was present in $55 \%$ of Preeclampsia and $66.7 \%$ Eclampsia cases. Hyper mature villi indicate severity of hypoxia. Incidence of hyper mature villi in Aparna et al (2011) study was 54\%. In present study incidence was $72 \%$ in pre-eclampsia and $66.7 \%$ in eclampsia. Incidence of stromal fibrosis was $56 \%$ in Maham et al study, while its incidence in present study in pre-eclampsia was $44 \%$ and $66.7 \%$ in eclampsia.

\section{Anaemia}

In the present study increased syncytial knots were seen in Anaemia (50\%). Similar changes were found in their study by Adil $\mathrm{S}$ et al in Belgaum and Rangnekar et al. ${ }^{7,8}$ In the present study, 50\% placentae of Anaemia group revealed increase in the number of villi with stromal fibrosis as compared to control group. These findings are consistent with the study of Rohini et $\mathrm{al}^{9}$ and Rangnekar et al. The difference between the two groups (Anaemia and Control) was statistically very significant $(\mathrm{p}<0.001)$. Adil $\mathrm{S}$ et al also found increased stromal fibrosis $(42.85 \%)$ in Anaemia.

\section{Diabetes mellitus}

Marilza VC et al in their study of histopathological placental lesions in mild gestational hyperglycemic and diabetic women, mean age of mother found 27.1 years. ${ }^{10}$ In the present study mean age of mother was found to be 30 years.

Varma $\mathrm{R}$ et al in their study 'Cellular changes in the placenta in the pregnancy complicated by Diabetes Mellitus' found mean birth weight of baby $3280 \mathrm{gm}^{11}$ Marilza VC et al found mean birth weight 3490 gms. In the present study mean birth weight was $3560 \mathrm{gm}$. consistent with above studies. In the present study gross macroscopic changes observed were calcification in $71 \%$ and infarction in $71 \%$. There was no evidence of retroplacental haematoma. Varma $\mathrm{R}$ et al found increased syncytial knots $(60 \%)$ and villous edema $(80 \%)$ in diabetic placentae whereas Marilza VC et al found villous edma in $37.5 \%$ cases of Gestational Diabetes Mellitus. In the present study, the prominent microscopic changes were increased syncytial knots $(71.4 \%)$ and villous oedema $(28.5 \%)$, consistent with the observations of Ranjana et al.

\section{Heart disease}

According to Clavero et al, in women with a wellcompensated Heart Disease irrespective of lesion during pregnancy, the placenta is usually normal in all aspects. ${ }^{12}$ In the present, no significant macroscopic and microscopic changes were observed in placentae from Heart disease. This was similar with observation of Clavero et al.

\section{CONCLUSION}

Majority of the placentae from abnormal pregnancy show pathological changes for which aetiology can be predicted, but quantitative estimation of placental changes is essential.

The placenta not only has the great potential to provide valuable information in cases of adverse fetal outcome, but may also bear the appropriate medicolegal responsibility.

The importance of immediate gross examination of all placentae and thorough microscopic examination in those cases where pregnancy outcome or placenta is grossly abnormal can be stressed. There should be a report and record of this examination and initial gross examination 
of the placenta is the responsibility of the clinician conducting delivery.

Gross and microscopic examination of placenta is strongly recommended in cases where maternal comorbid conditions are likely to have an adverse perinatal outcome.

\section{Funding: No funding sources}

Conflict of interest: None declared

Ethical approval: The study was approved by the Institutional Ethics Committee

\section{REFERENCES}

1. Joshi Vijay V. Handbook of Placental pathology. 1st Edition. Igaku-Shoin New York and Tokyo; 1994:110 .

2. Cunningham, Leveno, Spong. Implantation, Embryogenesis and Placental Development. Williams Obstetrics 18th Edition.1993;3:51.

3. Akhlaq M, Nagi AH. Placental morphology in preeclampsia and eclampsia and the likely role of NK cells. Indian Journal of Pathology and Microbiology. 2012;55(1):17-21.

4. Chhetri K, Shilal P. Assessment of birth weight and morphometry of placenta in pregnancy induced hypertension in Sikkimese population. Journal of Evolution of Medical and Dental Sciences. 2013;2(36):6988-94.
5. Dutta DK, Dutta B. Study of human placentae associated with Pre-Eclampsia and essential hypertension in relation to foetal outcome. Journal Obstetrics and Gynaecology India. 1989;39(6):75767.

6. Narasimha A, Vasudeva DS. Spectrum of changes in placenta in toxemia of pregnancy. Indian Journal Pathology Microbiology. 2011;54(1):15-20.

7. Adil SAK. A Study of Histopathological Changes of Placenta in Severe Anaemia. Journal of Evolution of Medical and Dental Sciences. 2012;1(1):616-23.

8. Rangnekar AG, Darbari R. Placental changes in pregnancy Anaemia. a study of 100 cases. Journal of Obstetrics and Gynaecology India. 1993;431(4):4738.

9. Rohini M, Yogesh AS, Goyal M, Praveen Kurrey. Histological Changes in the Placentae from Severe Anaemic Mothers. International Journal of Medical and Health Sciences. 2013;2(1):30-5.

10. Marilza VC, César P. Histopathological placental lesions in mild gestational hyperglycemic and diabetic women. Diabetology and Metabolic Syndrome. 2011;3:19.

11. Verma R. Cellular changes in the placenta in pregnancies complicated with diabetes. International Journal Morphol. 2010;28(1):259-64

12. Clavero JA. Measurement of villous surface in normal and pathologic pregnancies. American Journal Obstet Gynaecol. 1963;86:234-40.

Cite this article as: Patil SS, Siddheshware R, Sambarey PW. Clinical correlation with pathology of placenta in medical disorders of pregnancy and its comparison in normal pregnancy. Int J Reprod Contracept Obstet Gynecol 2017;6:127-32. 